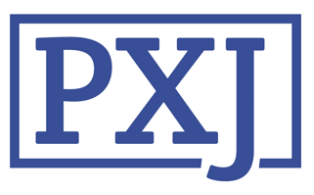

Patient Experience Journal

Volume 2 | Issue 2

Article 18

2015

\title{
Patient needs in advanced Renal Cell Carcinoma: What are patients' priorities and how well are we meeting them?
}

Rick Harris

Customer Faithful Ltd.

Kate Oake

Pfizer Ltd.

Robert E. Hawkins

Institute of Cancer Sciences, The University of Manchester

Robert J. Jones

Beatson West of Scotland Cancer Centre, Glasgow

Thomas Powles

The Royal Free NHS Trust and Barts Cancer Institute, London

See next page for additional authors

Follow this and additional works at: https://pxjournal.org/journal

Part of the Health and Medical Administration Commons, Health Policy Commons, Health Services Administration Commons, and the Health Services Research Commons

\section{Recommended Citation}

Harris R, Oake K, Hawkins RE, Jones RJ, Powles T, Montgomery DA. Patient needs in advanced Renal Cell Carcinoma: What are patients' priorities and how well are we meeting them?. Patient Experience Journal. 2015; 2(2):142-152. doi: 10.35680/2372-0247.1053.

This Article is brought to you for free and open access by Patient Experience Journal. It has been accepted for inclusion in Patient Experience Journal by an authorized editor of Patient Experience Journal. 


\section{Patient needs in advanced Renal Cell Carcinoma: What are patients' priorities and how well are we meeting them?}

\section{Cover Page Footnote}

Professor Hawkins reports grants from Pfizer, during the conduct of the study; grants and personal fees from Pfizer, grants and personal fees from GSK, grants and personal fees from Novartis, outside the submitted work; . Professor Powles has nothing to disclose. Professor Jones reports non-financial support from Pfizer, during the conduct of the study; grants and personal fees from Pfizer, grants and personal fees from GSK, outside the submitted work; . Mr. Harris reports grants from Pfizer Ltd, during the conduct of the study; grants from Pfizer Ltd, outside the submitted work; In addition, Mr. Harris has a patent 'Lifelines' - which is a trademark, registered by the UK Intellectual Property Office ref no UK00002545303 on 30 July 2010. K. Oake is employed by Pfizer Ltd and has shareholding in Pfizer Ltd Dr Montgomery is employed by Pfizer Ltd and has shareholding in Pfizer Ltd

\section{Authors}

Rick Harris, Kate Oake, Robert E. Hawkins, Robert J. Jones, Thomas Powles, and David A. Montgomery 


\title{
Patient needs in advanced Renal Cell Carcinoma: What are patients' priorities and how well are we meeting them?
}

\author{
Rick Harris, Customer Faithful Limited, UK, rick@customerfaithful.com \\ Kate Oake, Pfizer Ltd, Walton Oaks, SurreyUK, kate.oake@pfizer.com \\ Robert E. Hawkins, Department of Medical Oncology, Institute of Cancer Sciences, The University of Manchester, \\ Manchester,UK, rhawkins@picr.man.ac.uk. \\ Robert J. Jones, Institute of Cancer Sciences, University of Glasgow, Beatson West of Scotland Cancer Centre, Glasgow, UK, \\ r.jones@beatson.gla.ac.uk \\ Thomas Powles, The Royal Free NHS Trust and Barts Cancer Institute, Queen Mary University of London, London, UK, \\ thomas.powles@bartshealth.nbs.uk \\ David A. Montgomery, Pfizer Ltd,Walton Oaks, Surrey UK, david.montgomery@pfizer.com
}

\begin{abstract}
Treatment options and duration of therapy for patients with metastatic renal cell carcinoma (mRCC) have increased. Many patients now spend in excess of 2 years on active therapy. These patients' needs, and the ability of health services to respond to them, are poorly understood. Ten patients living with mRCC for more than 2 years and treated with at least one targeted agent were selected at random from three hospitals in the United Kingdom (UK). One interviewer who was not involved in their care conducted in-depth interviews. Interview transcripts were analysed using Interpretative Phenomenological Analysis (IPA) to identify issues of greatest importance to patients, and to understand how well patients felt their needs were being addressed. Perceived delay in initial diagnosis was a major theme. Being told the truth about treatment side effects upfront was important, but was often at odds with perceived delivery. 'Dealing with side effects', understanding dose and its effects and not letting 'negative thoughts get in' were highlighted as important, but were highly personal to patients and areas where patients struggled. Concordance was observed with delivery of 'a clear next step' for treatment, timely access to drugs and guidance on a drug 'holiday'. Patient experience of $\mathrm{mRCC}$ and its treatment requires a tailored approach. This research suggests there are key opportunities for service improvement and improved communication throughout the pathway to better meet the needs of patients, including non-clinical support to build personal resilience.
\end{abstract}

\section{Keywords}

Metastatic renal cancer, interpretative phenomenological analysis, IPA, patient experience, voice of patient, service improvement, service delivery

\footnotetext{
Note

Dr. Hawkins reports grants from Pfizer, during the conduct of the study; grants and personal fees from Pfizer, grants and personal fees from GSK, grants and personal fees from Novartis, outside the submitted work.

Dr. Powles has nothing to disclose.

Dr. Jones reports non-financial support from Pfizer, during the conduct of the study; grants and personal fees from Pfizer, grants and personal fees from GSK, outside the submitted work.

Mr. Harris reports grants from Pfizer Ltd, during the conduct of the study; grants from Pfizer Ltd, outside the submitted work; In addition, Mr. Harris has a patent 'Lifelines' - which is a trademark, registered by the UK Intellectual Property Office ref no UK00002545303 on 30 July 2010.

K. Oake is employed by Pfizer Ltd and has shareholding in Pfizer Ltd.

Dr Montgomery is employed by Pfizer Ltd and has shareholding in Pfizer Ltd.
} 


\section{Introduction}

Kidney cancer is the $8^{\text {th }}$ most common cancer in the UK, affecting almost 10,000 patients per year, and incidence has been increasingly rapidly ${ }^{1}$. At diagnosis, approximately $20-30 \%$ of renal cell carcinoma (RCC) patients will have metastatic disease. Of those presenting with localised disease at diagnosis, up to $30 \%$ will go on to relapse with distant disease ${ }^{2}$.

The prognosis for this group of patients with advanced disease has historically been poor. Cytokine therapies have been commonly used in the treatment of metastatic renal cell carcinoma (mRCC) but with anti-tumour effect limited to relatively few patients. Interferon- $\alpha(\mathrm{IFN}-\alpha)$ has an approximately $11-15 \%$ objective response rate in appropriately selected individuals ${ }^{3}$. Historical median survival has been around 14 months in patients treated with IFN- $\alpha$.

In recent years, there has been a rapid expansion of treatment options for these patients. Two classes of agents, anti-angiogenic agents targeting vascular endothelial growth factor (VEGF) and other pathways, and mammalian target of rapamycin (mTOR) inhibitors, have been licensed across various lines of therapy giving patients more generally efficacious treatment options. It is now possible to treat patients beyond three lines of effective therapy.

This step change in the outcomes that can be expected for patients presenting with $\mathrm{mRCC}$ has resulted in many more patients surviving longer with this disease. Moreover, unlike traditional chemotherapy regimens, these newer treatments are typically orally administered and are taken on a continuous basis while the patient continues to get benefit. Patients are now taking more targeted therapies at home in pill or capsule form. Once they have adjusted to their new treatment, many return to a good level of function, and some may return to work. In practice, little is known about the needs of people managing their life with advanced disease in this way, and whether these needs are being correctly identified and met.

In England, the Department of Health (DoH) has previously acknowledged the importance of identifying and meeting the needs of patients who are still living with their cancer alongside those who have had successful, curative treatment. This led to the creation of the National Cancer Survivorship Initiative (NCSI), a key part of the DoH's Cancer Reform Strategy when it was published in 2007. Survivorship has been retained in the more recent DoH publication 'Improving Outcomes: A Strategy for Cancer'4 with UK charity Macmillan Cancer Support, also known as Macmillan, as a key delivery partner.

Recently, the importance of patient experience has been further enshrined in the National Health Service (NHS) Outcomes Framework for $2013 / 145$, particularly at the end of life (defined as the final three months of life), with improving the experience of care for people at the end of their lives being stated as a priority for the NHS in England. Additionally, the NHS Outcomes Framework requires the NHS to strive to enhance the quality of life for patients living with long-term conditions, and to enhance quality of life for their caregivers.

But while there is much emphasis on improving patient care in this setting, and while some research has been undertaken into the needs of patients and their caregivers across a range of cancer types ${ }^{6}$, there has been little focus specifically on patients with $\mathrm{mRCC}^{7}$. Given the specific, and very recent, changes to the treatment of mRCC and the potential for significantly improved patient outcomes that these bring, it is important to fully explore whether the needs of this group of patients are currently being addressed.

The health and social care services previously organised and designed to look after these patients may no longer be fit for purpose, and patients may not have access to wider support and services outside the clinic environment. Increasing numbers of patients will be using services for longer, and the nature of the disease and the side effects of treatment have changed.

The current study aims to understand the needs of patients living longer term with metastatic renal cell carcinoma and to explore how well patients perceive their needs are being met by current services.

\section{Patients and Methods}

\section{Participants}

Ten patients attending renal clinics at The Christie Hospital (Manchester), Bart's and the London NHS Trust (London) and The Beatson West of Scotland Cancer Centre (Glasgow) were enrolled into the study. These participants were adults with stable mRCC diagnosed more than 24 months previously and who had been treated with one or more targeted therapies (including but not limited to sunitinib, sorafenib, pazopanib, bevacizumab, temsirolimus or everolimus). Initial entry criteria had included an upper limit of 36 months of treatment, but this criterion was removed during the study to facilitate recruitment. Participants were capable of giving informed consent to participate and of undergoing face-to-face interviews with investigators, either independently or through translators.

\section{Methods}

Interpretative phenomenological analysis (IPA), the key methodologies of which have been described elsewhere ${ }^{8}$, was employed in this study. Subjects underwent a single, 
one-to-one semi-structured interview, lasting typically between 60 and 90 minutes. Nine subjects were interviewed in their own home by the chief investigator, one by telephone. Consent was obtained to audio-record each interview in full so that the detailed line-by-line analysis of every conversation could be achieved.

The outline structure for the interviews was derived from extensive analysis of the literature carried out between December 2010 and January 2011. In particular, grey literature such as patient Internet chatrooms and for a dedicated to kidney cancer were included in the search. These sources were analysed similarly to the patient interviews (see below) and likely emerging themes were identified. Using these expected emerging themes, the interviewer was able to provide direction for the conversation if required. Moreover, the themes identified as likely to emerge from the review of the literature could be compared to areas proactively raised by patients during the interviews. Themes predicted to arise from the literature review prior to the interviews, and those summarised in Table 1. Open-ended questions were used to facilitate discussion, but the interviewees were free to tell their story in their own way.

\section{Data Analysis}

The Chief Investigator, who moderated the interviews, and a second researcher who completed an independent analysis carried out data analysis. IPA moderators are trained to suspend presuppositions and judgment whilst reading the text transcripts, in order to focus on what is actually presented in the transcript data. This involves the practice of "bracketing" - the suspense of critical judgment and a temporary refusal of critical engagement, which would bring in the researcher's own assumptions and experience ${ }^{10}$. However, IPA acknowledges a role for interpretation. Therefore, once the initial data analysis is done, the moderator conducts a second pass, adding their interpretation of the meaning of the data. This is then integrated across the two assessments of moderator and secondary researcher. Two complementary approaches were employed; thematic analysis and case study analysis.

The thematic analysis aimed to identify and code key areas of importance arising from the interviews, focusing on participants' experiences of the care they received. All interviews were transcribed in full to facilitate analysis. Each transcript was then manually coded, with the researchers creating a label for each patient comment, primarily regarding their experience and perspective of an issue. Line by line labeling of the transcript ensured all data were captured for the analysis. The researcher, providing interpretation of the meaning of the patient's comment, then added a further comment.
From these detailed codes, higher-level themes were established, aggregating similar experiences together, and phrased in the first person in order to represent a participant speaking. In addition, a further 'tag' was added which identified when in the patient's treatment pathway the issue occurred (e.g. at diagnosis).

For example, the following excerpt was labeled Panic \& Rationalisation and fell into the 'Diagnosis' point in the patient pathway:

"They wanted to put me through a scan ... could my daughter get my wife up there? I thought 'that was not sounding clever'. They kept me in ... The doctor came up and said "we can't deal with you in this hospital, we have got to send you to [another hospital]". ... "why can't you deal with it?" He said "because this is not lung cancer, this has come from your kidney". I thought 'Ob No!"”

The themes emerging from the interviews were then compared against the themes which were expected to emerge from the pre-work to identify any areas which were discussed previously in the literature, or are the focus of discussion on online support groups, but which were not raised by interviewees in this study (Table 1).

To determine how important each theme was, and how well current provision met the expectations of patients for this theme, all comments relating to each theme were grouped and assessed in the context of all the issues rose.

Where the same theme was raised repeatedly both within and across interviews, researchers interpreted this as of higher importance than those raised less frequently. For example, if all patients stated a need for early diagnosis, this was rated as more important than if only one patient made the comment. In addition, researchers sought to interpret the intensity of the issue rose. This was ascertained from a range of 'clues' including the type of language used and degree of emphasis placed. For example, high intensity was ascribed to an excerpt using words such as "terrifying" and "extremely worried". In this way, an issue that was of extreme importance to a few patients would be considered of similar importance to an issue raised by all patients, but without the same intensity.

Finally, using case study analysis, consideration was given as to how well each theme was delivered against by the current service and other sources. Where participants described their symptoms as not being recognised, a low level of 'delivery' was interpreted. For example, "I started getting pains round about my kidney area in my back. I went to the doctor a few times, and she kept saying it was an infection and different things". 
Table 1: 'Pre-fieldwork' shows the list of themes arising from desktop research and a literature review, including patient fora and chatrooms dedicated to kidney cancer. This informed the discussion guide (Table 4) for use in the patient interviews. 'Post fieldwork' shows the themes that were actually raised in the patient interviews. The four final high-level themes were plotted as 'journey steps' on the lifeline (Figure 2).

Pre-fieldwork
Symptoms and RCC diagnosis
1. No obvious symptoms
2. Confusion and disbelief - where did it come from?
3. Diagnosis comes out of the blue and is devastating
4. A death sentence - panic sets in
5. Playing with statistics

Getting over the shock and seeking options

6. A waiting game

7. Limited options

8. Getting informed and taking some control

9. Craving normality

10. No silver bullet or miracle cure

\section{Surviving mRCC}

11. A rollercoaster of emotions - coping with the constant ups and downs

12. Extending life and precious time

13. Life appreciation and 'bucket' lists

14. A constant fight - ready for the next hit

15. A different person

16. Clutching at glimmers of hope

17. Shared experiences and deep connections

18. Enduring the treatment and side effects - not giving up

19. Having a wellness plan

20. Financial burden

21. Family impact and support

\section{On-going monitoring}

22. Running out of options

23. Scanxiety - dread of mets

\section{Impending final days}

24. Fighting to the end

25. What you want, not what others expect

26. Submission

\section{Post-fieldwork}

\section{Symptoms and RCC diagnosis}

1. Out of the blue with no obvious symptoms

2. Panic and rationalisation

\section{Getting over the shock and seeking options}

3. Getting immediate attention

4. A plan of action

5. Getting the right information I can trust

6. Facing reality and acceptance

\section{Finding ways to cope}

7. Ups and downs \& complications

8. Time matters

9. A different normality

10. Coping day to day

11. A different person

12. Side effects, effectiveness and quality of life

13. Work and financial implications

14. Support around you

\section{Keeping stable}

15. Prepared to try anything and everything

16. Size matters (tumour)

17. Drug reliance and routine

18. Constancy of care
A visual illustration of the higher level themes and patients' experience of delivery against these was then developed, with themes placed chronologically from before diagnosis to present time on the 'lifeline' chart (see Figure 1).

\section{Results}

10 patients were enrolled into the study with equal numbers of men and women and an average age of 64 . Basic demographics for the patients, including date of first diagnosis and their initial treatment for metastatic disease, are presented in Table 2. 


\section{Emerging topics and themes}

As can be seen from Table 1, the themes which arose from both the pre-work and the interviews could be grouped into areas which formed a patient journey from initial symptoms and seeking help, through diagnosis and treatment and ultimately to discussions about end of life. But while the broad topics were consistent, 5 of these emerged in the pre-work, with only 4 emerging from interview, and the detailed themes which emerged differed between the pre-work and interviews in several areas.

Some of the pre-fieldwork themes were more desperate and fatal in tone than those arising in the interviews. The expected narratives of 'a death sentence', 'limited options', 'fighting to the end' and 'submission' were either reduced in their intensity or absent. Themes were more day-to-day in emphasis with patients generally on a more even keel, albeit reporting 'ups' and 'downs'.

The first two topics, 'symptoms and RCC diagnosis' and 'getting over the shock and seeking options' were very broadly consistent between the pre- work and the interviews. However, the next phase was described following the pre-work as 'surviving mRCC', with some emphasis on extending life and fighting cancer. This was altered after the fieldwork to 'finding ways to cope' with the interviewees talking much more about coping day-to- day and finding a new normality more than fighting cancer.

In the pre-work, the $4^{\text {th }}$ and $5^{\text {th }}$ topics were 'ongoing monitoring' and 'impending final days'. The pre-work identified a period where patients were anxious about scans, and about running out of treatment options, before a final stage where patients discussed end of life, death and dying. During interviews, this $4^{\text {th }}$ stage was much more about stability, both of tumour size on imaging as well as treatment regime. Fear of running out of options had been a major identified theme in the pre-work; a theme which did not emerge during the actual interviews.

Pre-work ahead of the study identified a $5^{\text {th }}$ topic, dealing with death and impending final days, as being of significant concern to patients with RCC and there is much discussion, particularly in online support groups, about fear of death in particular. When analyzing this study's results, it became clear that needs around death and dying are reflected in research conducted by Macmillan that led to the inclusion of 'I want to die well' in Macmillan's 9 outcomes, a series of nine statements that the charity developed with cancer patients and which they want every patient with cancer to be able to say by $2030^{11}$ (see Table 3). Interestingly, patients did not raise death or dying in this study. The methodology used here did not

$\mathbf{F}$

igure 1: The patient lifeline. Issues highlighted as important are grouped chronologically from left to right according to where they affect the patient during their treatment. How important these issues are (blue line) is graphed against how well the issues are being met (yellow line). Larger gaps between the lines suggest areas where the most work needs done to meet patient needs.

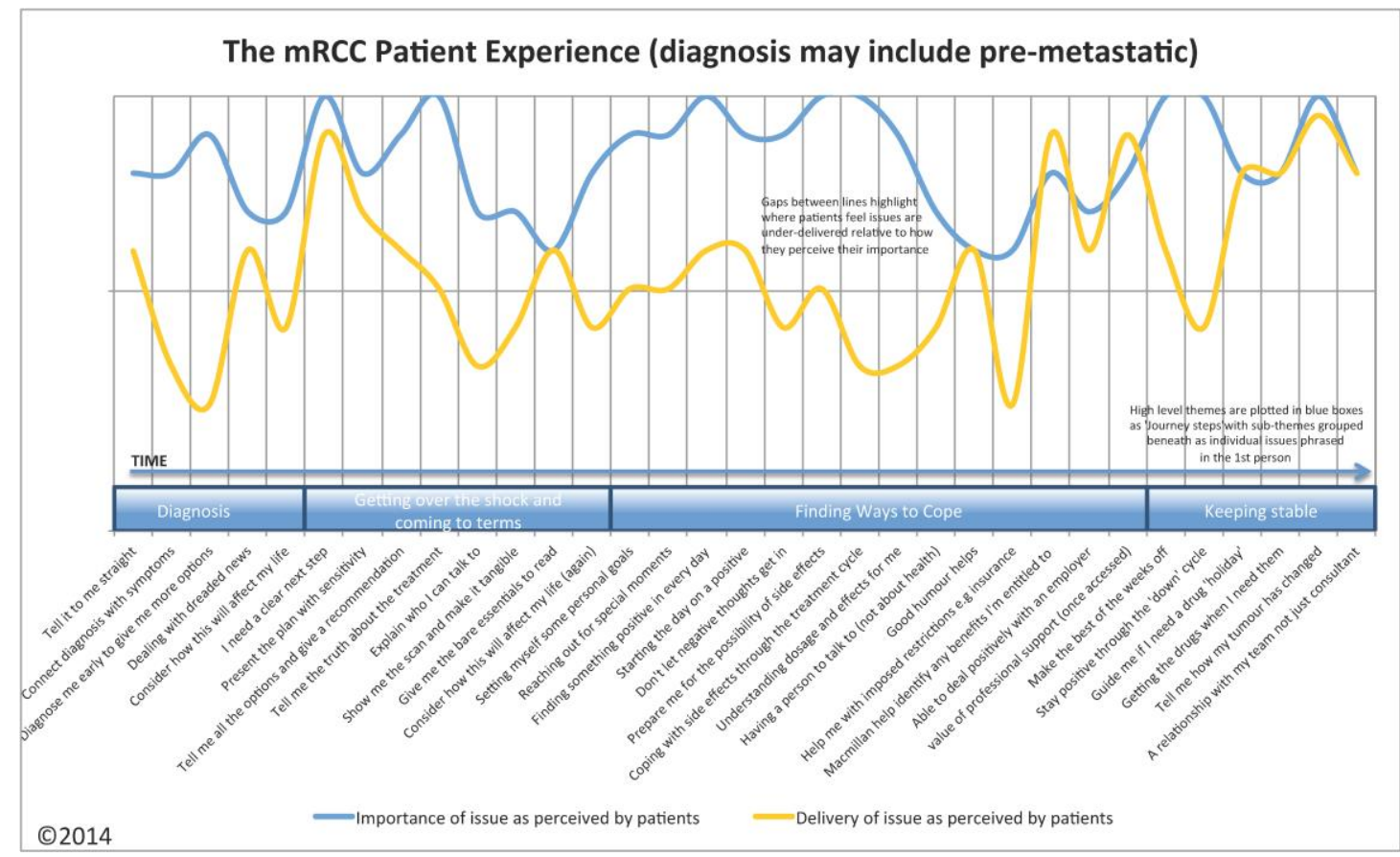


Table 2: Baseline characteristics of the included patients

\begin{tabular}{|l|l|l|l|l|}
\hline Participant & Gender & Age & Lead mRCC Treatment & Mate of mRCC diagnosis \\
\hline 1 & Female & 74 & sunitinib & Jan 2009 \\
\hline 2 & Female & 60 & sunitinib, interferon & May 2011 \\
\hline 3 & Male & 60 & pazopanib & Jun 2010 \\
\hline 4 & Male & 62 & sunitinib & Jan 2010 \\
\hline 5 & Female & 55 & sunitinib, radiation & Sep 2010 \\
\hline 6 & Female & 66 & pazopanib & Jan 2011 \\
\hline 7 & Male & 74 & pazopanib & Jul 2010 \\
\hline 8 & Male & 68 & pazopanib & Feb 2010 \\
\hline 9 & Female & 62 & sunitinib & Dec 2010 \\
\hline 10 & Male & 66 & sunitinib & \\
\hline
\end{tabular}

Table 3: Macmillan's 9 outcomes, a series of 9 statements that the UK charity Macmillan Cancer Support report that cancer patients want to be able to say in relation to their diagnosis and care.

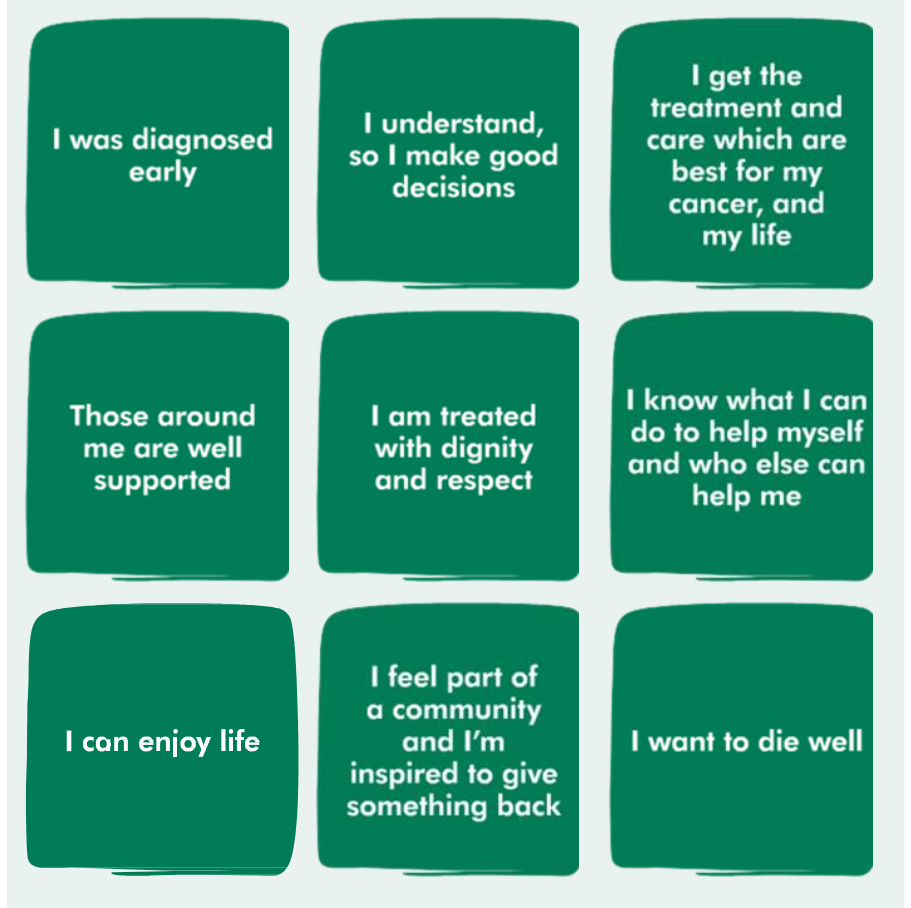


include proactively raising specific issues which were not raised by patients, so it is not clear what drove this lack of willingness to raise death in this forum.

\section{Lifelines}

The lifelines chart (Figure 1) takes the topics and emerging themes and displays them along with graphic representation depicting how important these issues were to the interviewed patients (blue line), and how well they were delivered to the patient (yellow line).

All of the issues listed are of importance to patients. Interestingly, in a large number of areas, the care, information or support that the patient received did not meet with their needs, as can be seen from Figure 1. The largest gaps between importance and under-delivery were observed in the following areas:

- Early diagnosis in order to have more options

- Coping with side effects through treatment

- $\quad$ Staying positive through the 'down cycle', or psychological or physical low points during treatment

- Understanding dosage and effects for them

- Being prepared for the possibility of side effects.

However there was significant under-delivery in a range of other areas including: connecting their diagnosis with symptoms; being told the truth about treatment; an explanation of who there is to talk to, including outside the clinical team; personal goal setting; reaching for special moments; finding positives every day; gaining help with imposed restrictions, such as travel insurance; and making the best of any time off treatment.

In very few areas did delivery of care match or exceed the expectations of the patients. The value of Macmillan in helping access financial benefits and the value of other professional support (when accessed) were two such areas, as were getting the right drug when needed, being given treatment breaks where necessary, being told about changing tumour size and a relationship with the whole team, not just the consultant.

For the first main topic, diagnosis, of particular concern is that under-delivery started even before a diagnosis. The patients in this study highlighted a failure to connect the symptoms with which they had been suffering to their eventual diagnosis, and were upset that the late diagnosis left them with few options for treatment, and no prospect for cure.

The second main topic identified in this study was 'getting over the shock and seeking options'. At this point, the participants of this study required a clear next step, and a plan of action delivered with sensitivity. Overall, these requirements were met for the patients in this study,

No patient in the sample cohort proactively raised wanting to use the internet to access comprehensive details of their condition. However, most wanted a simple, truthful explanation of their condition, their prognosis, and a clear next step, as well as a recommendation from their consultant as to the best course of action. Patients also wanted to feel involved, and to have all the facts about their cancer provided. In particular, patients in this study wanted to see scans and 'make it tangible'. The delivery of

Figure 2: The relative proportions of time individuals feel like a 'patient' compared with feeling more normal (like a 'person').

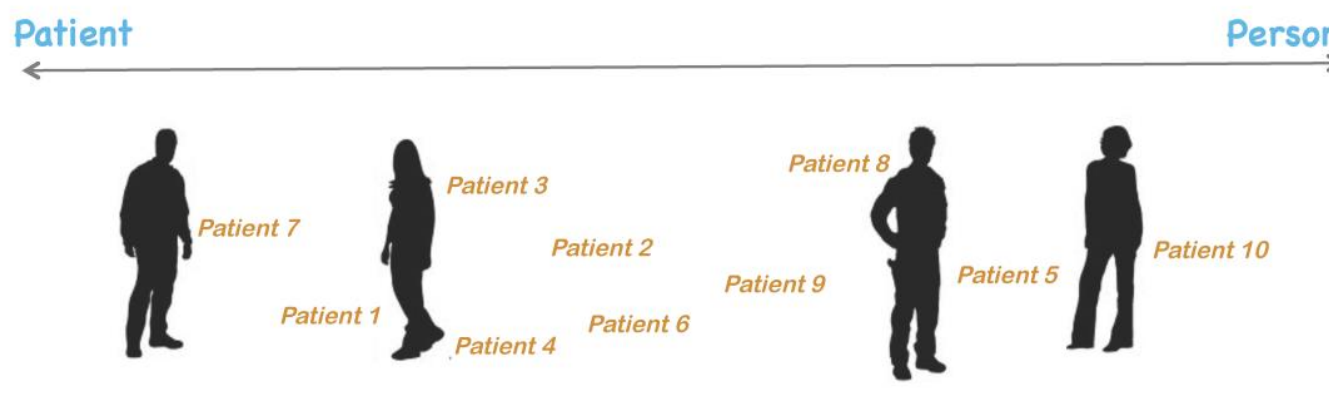


the above was not provided consistently, but elements of each were reported.

Macmillan nurses were highly valued for support at this stage, even if their initial appearance at diagnosis was feared by loved ones as a sign of more significant disease.

One patient stated "The first I really heard of it was when I read the piece of paper and I saw the word 'tumour'. I thought 'I hope there is not a Macmillan nurse there', and this other woman walked in and she has got a Macmillan nurse and I thought 'ob shit'. I was in almost blind panic then"

\section{'Patient' or 'Person'?}

'Finding ways to cope' was a major topic in this study. The themes, which patients identified as important under this topic, were a mixture of external (such as being well prepared by hospital staff for the side effects of medicines) and internal (such as finding something positive in every day or not letting negative thoughts in). The participants in this study very consistently identified a balance between patient and person as being important for them in finding ways to cope. Patients varied during their treatment as to where this balance lay for them, but there was even greater variation between patients as to where they spent the majority of their time (Figure 2). The extremes of this spread are summarised by two patient quotes. Patient 1 , who feels like a 'patient' the majority of the time, stated, 'Now the side effects and treatment are worse than the cancer itself. Not long-term of course, but on a living my life day-to-day level, much, much worse. I'm on treatment and oh boy ... then it's just about getting through each day of the cycle and to the end of it, to feel whole again.

It makes me feel like two people. One who's fine, normal, humanthe old me; the other one who's really sick and has a terminal disease and there's no going back....'

In contrast, patient 8 managed to find more of a positive balance, claiming to feel more like a 'person' than a 'patient' for the majority of the time. Patient 8 stated, 'Yes I have cancer but I just don't let it get to me. I'm not the only one and I don't want to waste my life feeling sorry for myself. I'm lucky actually - I have my husband, children and grandchildren. They keep me going.

It's about living day by day but also setting targets. Like when we celebrated our $45^{\text {th }}$ wedding anniversary.

They told me the outlook was not good - maybe a year. Well that was 3 years ago so I've beaten that so what's stopping me now? Yes sometimes the side effects can be inconvenient but nothing worse than other illnesses. There are some things I can't always do or need belp with but then I'm not getting any younger anyway'.

Patients described the importance of setting personal goals, finding something positive to focus on, starting the day positively and avoiding negative thoughts. But patients were not always able to achieve this. Patients in this study were conscious that treatment optimization, and especially optimization of drug dosage, are key to achieving tumour control but also impact side effects. By balancing control of disease effectively against presence of side effects, patients were best able to define themselves as a 'person', rather than a 'patient' for more of the time, and this definition of self as 'person' was a key to remaining positive.

Those patients that had developed a trusting relationship with their clinic nurse in particular felt most engaged in the achievement of such balance. In particular, some nurses would suggest a 'drug break' if they felt that the patient would benefit from a relief or freedom from side effects for a period of time. Some patients were wary of coming off a treatment that was limiting tumour growth, but recognised that their endurance of side effects had its limits. Set against this balance, patients felt the nurse best identified the consideration of a drug break.

Few patients in this study turned to professional care support services on a regular basis. Instead, most turned to their spouse and occasionally children to provide care, not just for functional help but moral support, and simply to provide company. Some mentioned that having access to friends (non-family) to be able to discuss non-clinical issues (sport, hobbies, current affairs) provided a welcome distraction from introspection towards their condition. Few individuals mentioned being able to obtain support from the wider RCC community, and indeed some actively did not want to reach out to such a community.

Where professional external organisations did add significant value was in support for managing finances, such as getting access to entitled benefits. In particular, Macmillan was praised for helping patients access the benefits they were entitled to. This was important to patients, who described issues of work, and the financial pressures of not being able to work, as being of particular concern to them and their families. The role of an employer was often key. Some were described as exemplary in offering flexibility and support, whilst others added to the stress, with patients needing personal legal support to settle their employment situation. Advice and support for dealing with employers was very difficult to come by, and would be welcomed by patients.

The balance of factors exerting their effects on patients drove this variation between patients, and the extent to which the patient or the person predominates. These were:

- Patient disposition (optimist or pessimist, resilience)

- External factors, such as family support, financial concerns, existence of dependents, etc.

- The amount of focus on the malignancy

- Treatment cycle and especially side effects 
- External events, such as Computed Tomography (CT) scan results.

Of these, the impact of toxicity was, in this study, particularly high, but also very variable. This was true whichever of the two medicines were used, but we have focused on the 6 patients who received sunitinib to demonstrate that variability.

Of the patients on sunitinib, patient 10 had relatively little toxicity, and showed little fluctuation in mood over the 6 week cycles. Patient 9 had more toxicity, and cycled between feeling like a 'patient' during the 4 weeks on treatment, and feeling more like a 'person' during the two weeks off. Finally, patient 1 had toxicity which they perceived very negatively, such that the negative impact extended even into the off treatment period, resulting in ongoing anxiety about restarting treatment.

The final topic of concern to patients was 'keeping stable'. This applied both to mood and to the tumour size and clinical response. Patients valued drug holidays where possible to help offset side effects, as well as close relationships with the whole of the multi-disciplinary clinical team to help them feel they were getting access to the best advice in a timely manner. Again, a theme that emerged in this topic was that of being told honestly about how the tumour was doing, and even being shown the scans if possible. Tumour size and stability was perceived by patients as both a tangible measurement of stability as well as easy to present and understand in lay terms. In this study, patients felt very included in their management and were extremely appreciative of this involvement.

\section{Discussion}

The treatment environment for $\mathrm{mRCC}$ is changing rapidly, but the impact of these changes on patients' needs and expectations, and how well these are met in practice, has been poorly studied.

The current study was designed to use in-depth interviews with patients, assessed using IPA, to understand the needs of patients living long-term with $\mathrm{mRCC}$, and to explore their perceptions of how well these needs are being met. In addition, the authors sought to explore attitudes to any external support services and networks, and how and where such services could be improved.

Poor RCC outcomes in the UK is a particular concern, with only two countries in Europe (Denmark and Bulgaria) having a lower 5 year survival ${ }^{12}$. Among proposed explanations is late diagnosis in primary care, and this study certainly appears to add some weight to that theory. With the incidence of kidney cancer rising so quickly, it is imperative more is done to educate primary care physicians and members of the public on the need to seek expert advice for persistent suggestive symptoms. In analyzing the study results, some progress has been made with the commissioning of national campaigns to increase public awareness and encourage presentation in primary care $^{13}$.

The diagnosis of RCC is one that comes with quite significant shock to patients. A strong and effective multidisciplinary team, including excellent nursing support, is crucial to delivering a 'clear next step' and a plan of action clearly, simply and sensitively, as this had a direct impact upon the patients' ability to develop coping mechanisms. Such a team could also equip patients to prepare earlier, including developing an understanding of side effects, and discussing options for dealing with them.

As the role of the Macmillan nurse is reported to be very important, perhaps more could be done to introduce the Macmillan nurse in such a way as to mitigate some of the fears that patients associate with this job title. This fear may also lie behind the decision of some patients not to utilise the nurses' services from the start but patients valued being aware of them. If and when the need to use them came, speed of delivery was essential (and was reported to be excellent).

A significant focus of patients in this research was characterised by 'finding ways to cope'. It was under this topic in particular that the major themes identified as important to patients were least well delivered against. At the time of the pre-work, there were no routinely available treatment options for patients whose disease had progressed on first line sunitinib or pazopanib in the UK. In the time between the pre-work being conducted and the study opening to recruitment, further treatment options became available to patients. It would be worth exploring further what psychological impact limited access to treatment has on patients in the current climate of budgetary restrictions and restricted medicines access.

Regular treatment breaks associated with sunitinib appeared to help participants in this study establish a better balance between 'patient' and 'person'. This observation could lend support to the exploration of regimens, which include planned treatment breaks such as permitting 'drug holidays' (where patients with on-going clinical benefit from a drug discontinue the drug only to restart the same treatment when there is evidence of disease progression). One such study is underway in the $\mathrm{UK}^{14}$.

It is interesting to note that whether or not they were delivered against, eight out of nine Macmillan patient outcomes statements, which have been developed with patients who have a form of cancer, would certainly appear to be applicable to the patients in our study. There was a lack of expressed desire to be part of a wider cancer community and the statement 'I feel part of a community and I'm inspired to give something back' was not 


\section{Table 4 - Discussion Guide}

\section{PART 1: INTRODUCTION}

Introductory Statement:

Our discussion today is really all about your personal experience of living with ......

One of the topics we're likely to cover is your experience of medicines, including any possible side-effects you may have experienced. Should this happen, we are required to report these details to the sponsor of our study, who is a manufacturer of medicines. This is so that they can learn more about the safety of their medicines, esp. as some side effects may not be discovered until many people have used a medicine over a period of time. Everything else we discuss today will be treated in confidence and made anonymous - it is solely if you mention a side effect you, or someone you know, has experienced. Are you happy to proceed with the interview on this basis?' [If yes] - So, we have a little bit of paperwork to complete before we start, with a few statements to read, and you'll find one of them talks about "adverse events" - this is what healthcare professionals tend to call side-effects.

Establish rapport:

- how are you feeling today?

- How has your day been so far?

\section{PART 2: YOUR EXPERIENCE}

1. Can you tell me about how this all began?

PROMPTS: early signs or symptoms? Explanations to yourself? Your awareness?

Where did you look for information / advice / help?

2. And from that point of awareness, how did you get to a point of getting a diagnosis?

PROMPTS: length of time, stages described, accuracy

3. What was your experience of doctors and the medical profession at the diagnosis stage?

PROMPTS: What was good, what was bad? What would have helped?

4. What can you tell me about your thoughts and emotions after diagnosis?

PROMPTS: sharing the news with family and friends, other relationships, work and other roles

5. At that stage what were your priorities?

PROMPTS: longevity, quality of life, alleviating symptoms, gaining control

6. What were your thoughts and feelings about treatment or treatment options?

PROMPTS: role of medical practitioners, treatment centres, managing symptoms, dependency on treatments, what is good, what is bad?

7. What are your thoughts about keeping going with the treatments?

PROMPTS: motivation? Influences? What would help improve treatment?

8. Can you describe day-to-day living for me a little? The ups-and-downs?

PROMPTS: what makes for a good/bad day? Missing from the past? Expectations? Emotions? $\backslash$

9. Aside from the physical changes, to what degree do you think living with your condition has changed you as a person? PROMPTS: your attitude / character? Outlook? Relationships? Gained/lost? Have changes been slow, steady, sudden?

10. What helps you cope with everyday life?

PROMPTS: Adaptions, coping mechanisms? Identified by? (trial/error, advice)

11. And can I ask what areas of life are more difficult to cope with? What are the things that you would most want to improve / recover more normality of?

PROMPTS: Activities, family/relationships, ambition/achievement

\section{LOOKING FORWARD}

11. What are your priorities now? And for the future?

PROMPTS: Longevity, well-being, wellness plan, financial planning/mgt, alleviation of symptoms etc.

\section{THANK AND CLOSE}

Table 4: The above discussion guide with thematic prompts was used to aid structure within the conversation, without restricting or leading the interview flow unnecessarily. The discussion guide was not used as a set of questions to be systematically asked. Instead, it was used flexibly, supporting the participant to tell their own individual story, and the moderator to be an 'active listener'. Prompts were used where the interview lacked its own spontaneous course and to help establish rapport and rhythm to the interview. IPA methodology encourages the participant to set the parameters of the discussion and to follow the path of their own experience. This is key, as a predetermined set of criteria may not all have been relevant for each of the 10 narticinants. 
articulated by our patient group as important, and perhaps should be reconsidered by Macmillan.

Caution should be exercised before extrapolating our findings to the broader cancer population, or indeed the broader mRCC population. The patients studied here were from a sizeable group of outliers in that, for the most part, they had significantly exceeded 'average' life expectancy from this disease and had been on treatment for significantly longer than the average duration. This may well have impacted on various observations - for example, the failure of these patients to pro-actively raise the issues surrounding terminal care may reflect the fact that these patients were all some distance from the time of initially being told of their terminal prognosis, and none of them were imminently entering the terminal stage of their illness. It is quite possible that a group of patients who were experiencing an altogether shorter journey from diagnosis to death would have put much greater emphasis on this aspect. Conversely, the effects of chronic treatment side effects are likely to be of higher impact in the population studied here.

Given the variation that exists, the care and treatment of patients with mRCC needs to be individualised not only in relation to drug treatment but the targeting and provision of information, and of clinical and non-clinical support services. Further work to understand how best to assess the changing needs of patients with mRCC over time could prove valuable.

\section{Summary}

The current study provides rich insight through individual patient narratives into the many challenges which the welcome improvement in renal cancer outcomes have provided in recent years.

The lifelines chart demonstrates which issues are important to patients, and provides good insight into where their important concerns are, or are not, being met.

\section{References}

1. CRUK. Kidney Cancer Statistics. CRUK [ 2013 [cited 1013 Nov. 14]; Available from:

URL:http://www.cancerresearchuk.org/cancerinfo/cancerstats/keyfacts/kidney-cancer/

2. Rabinovitch RA, Zelefsky MJ, Gaynor JJ, Fuks Z. Patterns of failure following surgical resection of renal cell carcinoma: implications for adjuvant local and systemic therapy. Journal of Clinical Oncology [ 1994 12:[206-212]

3. Tsui KH, Shvarts O, Smith RB, Figlin RA, et al. Prognostic indicators for renal cell carcinoma: a multivariate analysis of 643 patients using the revised 1997 TNM staging criteria. Journal of Urology [ 2000 163:[1090-1095]

4. Department of Health. Improving outcomes, a strategy for cancer. 2011 Available from: URL:http://www.dh.gov.uk/prod_consum_dh/grou ps/dh_digitalassets/documents/digitalasset/dh_1233 94.pdf

5. Department of Health. The NHS Outcomes Framework 2013/14. 2013 Available from: URL:https://www.gov.uk/government/uploads/syst em/uploads/attachment_data/file/213055/121109NHS-Outcomes-Framework-2013-14.pdf

6. Cancer Survivorship Ingrid Ingrid Torjesen. (2010) 25 March 2010 Health Service Journal supplement, 1-3

7. Researching the experience of kidney cancer patients K Taylor. (2002) European Journal of Cancer Care 11, 200-204

8. Smith JA, Osborn M. Interpretative Phenomenological Analysis. Qualitative Psychology. Sage Publications UK; 2007. 53-80.

9. Husserl E. Ideas I. In: Welton D, editor. The essential Husserl: Basic writings in transcendental phenomenology. Indiana University Press; 1999.

10. Spinelli E. The mirror and the hammer: challenging orthodoxies in psychotherapeutic thought. Sage Publications UK; 2002. 32.

11. Macmillan Cancer Support. Improving cancer patient experience - a top tips guide. 2012 Available from: URL:http://www.macmillan.org.uk/Documents/Ab outUs/Commissioners/Patientexperiencesurvey_Top tipsguide.pdf

12. Angelis RD, Sant M, Coleman MP, Francisci S, Baili $\mathrm{P}$, Pierannunzio D et al. Cancer survival in Europe 1999-2007 by country and age: Results of EUROCARE-5 - a population based study. The Lancet Oncology 2014; 15(1):23-34.

13. Cancer Research UK (CRUK). 'Blood in Pee' campaign. (2014) Available from: URL: http://www.cancerresearchuk.org/healthprofessional/early-diagnosis-activities/be-clear-oncancer/blood-in-pee-campaign

14. Collinson FJ, Gregory WM, McCabe C, Howard H, Lowe C, Portrata B et al. The STAR trial protocol: a randomised multi-stage phase II/III study of sunitinib comparing temporary cessation with allowing continuation, at the time of maximal radiological response, in the first-line treatment of locally advanced/metastatic renal cancer. BMC Cancer 12[598]. 2012. 